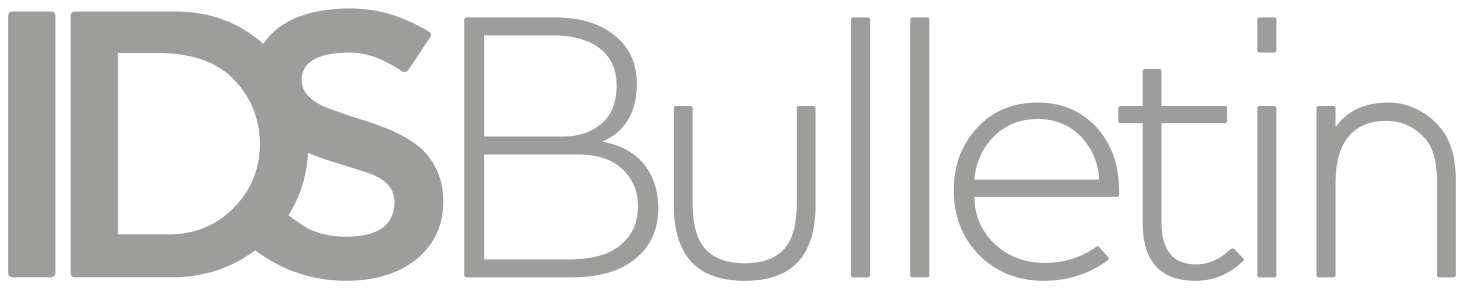

Transforming Development Knowledge

Volume 47 | Number 4 | September 2016

\title{
FORESIGHT IN INTERNATIONAL DEVELOPMENT
}

Editors James Sumberg and Gioel Gioacchino

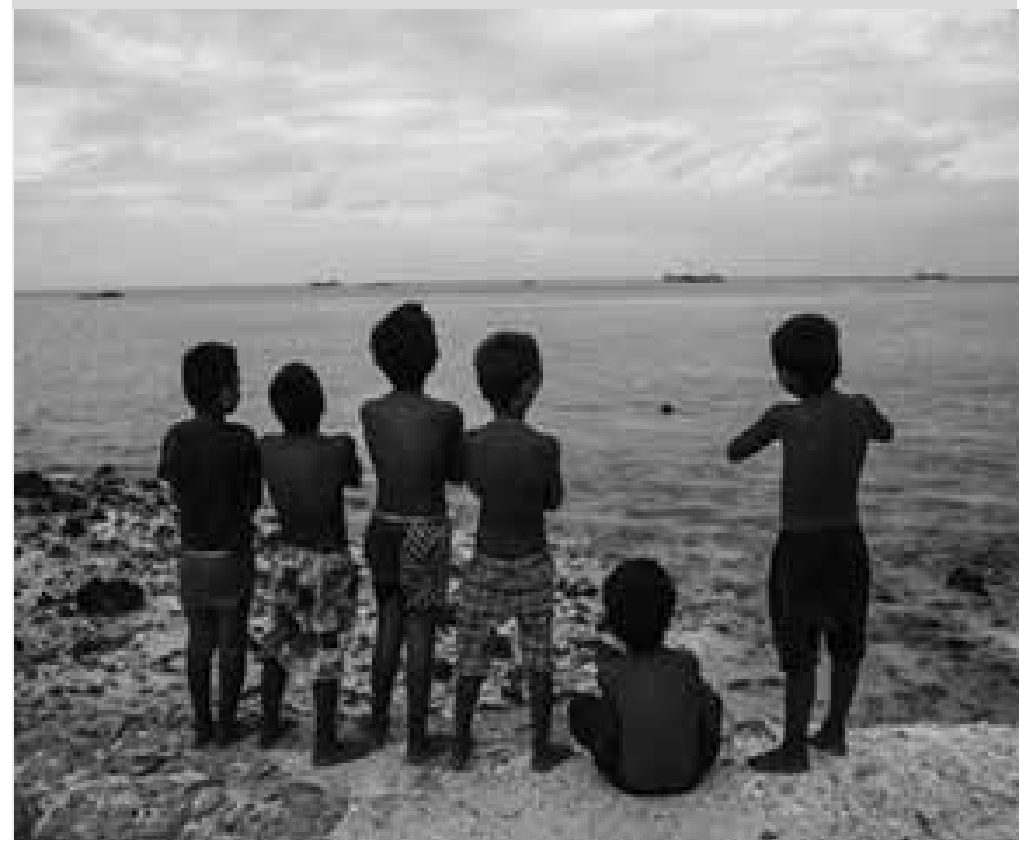


Notes on Contributors

Introduction: Foresight in International Development

Gioel Gioacchino and James Sumberg

Foresight and International Development

Kate Bingley

Models for Foresight Use in International Development

Alun Rhydderch

Agrimonde and Agrimonde-Terra: Foresight Approaches Compared

Marie de Lattre-Gasquet and Sébastien Treyer

A Foresight Scenario Method for Thinking About Complex Sustainable Development Interactions

Dominic Glover, Kevin Hernandez and Alun Rhydderch

Food Insecurity: The Future Challenge

Robin Bourgeois

Managing Waste in India with Foresight

Ashish Chaturvedi and Jai Kumar Gaurav

\section{Where Next for Social Protection?}

Stephen Devereux, Keetie Roelen and Martina Ulrichs

Cities, Violence and Order: The Challenges and Complex Taxonomy of Security Provision in Cities of Tomorrow

Jaideep Gupte with Stephen Commins

Glossary 


\title{
Where Next for Social Protection?'
}

\section{Stephen Devereux, Keetie Roelen and Martina Ulrichs}

\begin{abstract}
The rapid ascendancy of social protection up the development policy agenda raises questions about whether its current prominence will be sustained, or whether it will turn out to be just another development fad. What trajectory will social protection follow, which actors will drive it forward and what will be the main issues and challenges? This article reports on a small foresight study designed to address the question: 'Where next for social protection?' A scenario-building exercise revealed that there is no single linear pathway for social protection, but multiple highly context-specific trajectories subject to change as political ideologies and institutional capacities shift. A 'wind-tunnelling' exercise highlighted the importance of a country's political regime as a fundamental determinant of which social protection policies will be adopted. Better understanding of political processes is needed to protect gains made in social protection against possible reversals when the political climate shifts against pro-poor redistributive policies.
\end{abstract}

Keywords: drivers of change, foresight, rights-based approaches, scenario-building, social protection, wind-tunnelling.

\section{Introduction}

Social protection is incontrovertibly one of the success stories of development policy in the early twenty-first century. Every year new social protection programmes are launched, more countries adopt a National Social Protection Policy (NSPP) or Strategy (NSPS), and evaluations generate further empirical evidence of positive impacts. Current trends in social protection thinking and practice are taking two potentially contradictory directions - crudely, 'rights-based' versus 'growth-oriented' - which have different implications for who should receive what types of support, under what conditions and for how long.

1 Rights-based: institutionalising social protection in national policy frameworks, underpinned by legislation that endows justiciable claims to social protection entitlements to all citizens or residents, including refugees;

2 Growth-oriented: using social protection instrumentally, as a toolkit for achieving poverty reduction and economic growth; for example, by 'exiting' participants out of programmes when they reach a 'graduation' threshold. 


\begin{tabular}{llll}
\hline & 2000 & 2015 & 2025 \\
\hline (a) Expansion & & & \\
Social protection continues to grow & & \\
both conceptually and operationally, \\
generating interesting new issues to \\
research, new policies to design and new \\
programmes to evaluate.
\end{tabular}

\section{(b) Plateau}

Social protection becomes entrenched as a permanent fixture of development discourse, consolidating its place in government and donor policy and steadily increasing its coverage.

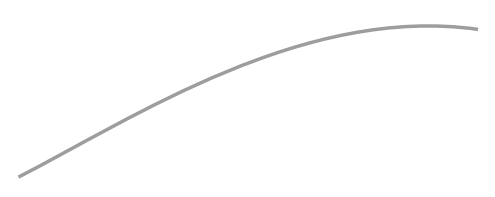

\section{(c) Decline}

Social protection becomes just another development fashion that follows a conventional project cycle, peaking around 2015 but declining thereafter, just as rapidly as it rose.

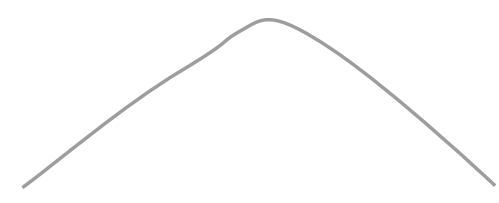

Source Authors' own.

The trajectory of social protection as a policy discourse deserves scrutiny. Although 'social safety nets' were introduced as a response to economic crises in the 1980s or earlier, the broader concept of social protection originated in the late 1990s. It was encapsulated first in the World Bank's growth-oriented 'Social Risk Management' framework (World Bank 2001), and later advanced by rights-based frameworks such as the Institute of Development Studies' (IDS) 'Transformative Social Protection' (Devereux and Sabates-Wheeler 2004) and the International Labour Organization's 'Social Protection Floor' (ILO 2011). In the mid-2000s the analysis shifted to specific design issues (e.g. targeting, dependency syndrome) and efforts to build the evidence base on impacts of specific instruments (e.g. conditional cash transfers, school feeding). In the 2010 s the focus has moved on to establishing social protection as a policy sector within government ministries and to challenges of coordination and systematisation (e.g. building a 'single registry').

Since the introduction of social safety nets in the 1980s, social protection has expanded greatly as a component of social policy. Common indicators used to measure this growth include the number of social protection policies in place, the percentage of the population covered by such policies and the proportion of public expenditures allocated to social protection (ILO 2014). The 'Social Protection Index' (ADB 2013) captures both the 'breadth' and 'depth' of social protection coverage, measured by the number of beneficiaries and the level of benefits provided by social protection programmes.

This crude trajectory raises an obvious question: where next for social protection? We identify three broad potential scenarios: (a) expansion; (b) plateau; (c) decline. 
Against this backdrop, we undertook a small-scale foresight project that aimed to:

1 critically review the policy discourse on social protection since its origins in the late 1990s and how it has been shaped by the main influencing actors;

2 identify and explore themes that are likely to be high on the social protection agenda in the short to medium term;

3 identify drivers of change that are likely to shape the social protection landscape in the medium to long term and to develop and test future scenarios for social protection;

4 identify entry points for responding to future themes, challenges and opportunities that will shape the future of social protection and determine appropriate forms of ongoing engagement.

This article is structured as follows. Section 2 describes the methodologies used for each component of the research. Section 3 explores the 'drivers of change' likely to affect social protection in the coming period, under the five 'STEEP' categories: social, technological, economic, environmental and political. Section 4 unpacks expected trajectories of social protection by considering the main issues and debates that might affect which trajectory is actually followed. Section 5 looks forward by describing potential future scenarios and policy options for social protection in the next 10 to 15 years, drawing on the foresight methodology. Section 6 concludes.

\section{Methods}

An eclectic mix of methods was designed and implemented, which included a background literature review; structured one-on-one interviews with key informants active in social protection policymaking, conceptualisation or research; a moderated online discussion event that engaged a wider audience working on social protection across the world; and two face-to-face foresight workshops.

The Centre for Social Protection (CSP), with the support of Knowledge Services at IDS and Elliptics Ltd, facilitated an online discussion event on the topic 'Where Next for Social Protection?', which ran for four days in September 2014. The discussion was structured around four questions, one for each day.

Day 1 - Predicting the future: Do you think that social protection will become more or less prominent in the development policy agenda in the next five to ten years? Why?

Day 2 - Issues and debates: What will be the most important issues and debates in social protection in the next five to ten years?

Day 3 - Drivers of change: What will be the most important drivers of change affecting social protection in the next five to ten years? 
Day 4 - The way forward: What needs to be done, and by which actors, to ensure that social protection remains high on the development policy agenda in the coming five to ten years? What can we do?

More than 200 participants registered for the online discussion from all over the world. Just over half of the participants came from or were based in Africa, Asia or Latin America, while just under half came from Europe (including the UK) or North America. Altogether 138 postings were made at an average of 34 postings each day.

Two foresight workshops were hosted by the Centre for Social Protection at IDS, in September and November 2014. The workshops brought together 18 people who work intensively on social protection, from research institutes, donors and non-governmental organisations (NGOs). Three forecasting methods were used in the workshops: drivers of change analysis, scenario building and wind-tunnelling.

Drivers of change analysis: Workshop participants brainstormed around the driving forces in the broader contextual environment that are likely to influence the direction of social protection programming over the next 10 to 15 years, under five 'STEEP' categories - social (demographics, lifestyles, social trends, etc.); technology (ICTs, media, etc.); economy (economic policies, growth rates); environment (climate change, natural resource management), and politics (welfare regimes, development policies and international aid flows).

Scenario building: Workshop participants selected two of the most powerful drivers identified in the 'drivers of change' exercise, and constructed four scenario 'spaces', using one driver as an x-axis and the other driver as a y-axis to create four quadrants. These scenarios were developed into narratives by reflecting on what kind of world each quadrant would represent, and the implications of that possible future world for social protection programming.

Wind-tunnelling: Next, the participants proposed several possible social protection policies to be introduced into the scenarios, and discussed how effectively each policy would perform given the contextual situation described for each scenario. The purpose was to identify what is possible in terms of robust social protection measures under different possible future conditions in specific country contexts.

\section{Drivers of change}

Drivers of change were considered in five categories: social, technological, economic, environmental and political (STEEP). These drivers were identified and assessed using all methods in this project. Findings from the literature review point towards historical drivers of the current state of social protection, while findings from the key informant interviews, online discussion and foresight workshops consider drivers that are deemed likely to play important roles in shaping the future world in which social protection will operate. 
A number of social factors emerged across all different methods of investigation in this project, including increasing inequality, demographic shifts and urbanisation.

Rising inequality has incentivised governments, particularly in middleincome countries, to introduce social protection as a redistributive mechanism. Various key informants pointed towards the potentially dangerous social impacts of inequality and the role for social protection as a palliative mechanism that can enhance social cohesion. In contexts with high levels of income inequality, social protection is more affordable since there is usually a larger tax-base to finance it with domestic resources (Hickey 2008), while in contexts with high levels of social inequality the associated political volatility has triggered increased investment in social protection. So income and social inequalities have consequences on both the supply- and demand-side.

Demographic shifts will transform the composition of societies. Some countries will be confronted with a 'population dividend' provided by a large percentage of young people, while others are already foreseeing an increasing need for pensions due to a growing proportion of older people. Will a higher demand for social protection for particular groups of society translate into more and better-quality supply? During the online discussion, some thought that the key question is whether population ageing stimulates the expansion of social protection - and especially pensions - or will ultimately lead to its unaffordability (or both).

Higher levels of urbanisation also increase the need for social protection since rural-urban migration often disrupts traditional (rural) safety nets. Social protection has traditionally focused on the rural poor and has developed instruments which address particular vulnerability profiles. However, the types of vulnerabilities change when people move from rural to urban areas, as increasing numbers of poor people are doing, and lose their community-based safety nets and social capital in the transition from rural livelihoods to mostly informal paid work.

Urbanisation not only increases the need for formal social protection to reduce vulnerability among the labour force, but also increases the demand for social protection by 'urban citizens' who are more likely to mobilise and lobby for their rights. Niño-Zarazúa et al. (2012) argue that the higher levels of urbanisation in middle-income countries have played a role in determining the socialisation of formal social protection, in comparison to low-income countries. Labour market structures in urban areas are still characterised by high levels of informality, mobile workers and gaps in the provision of social security for the poorest. This does not only affect migrants from rural areas but also international migrants, particularly as eligibility for social protection is often tied to citizenship status. This raises the question of how social protection will have to change to fill these gaps and address the new sets of emerging vulnerabilities. 
Technological factors were not considered to be greatly important in shaping the future landscape for social protection, other than in the delivery of social transfers (World Bank 2012). However, two additional technological factors were considered in the workshops. Firstly, the role of technology in changing skills requirements in labour markets, shifting demand for labour even further towards high-skilled labour, may have implications for the demand for social protection, particularly for low-skilled workers. Secondly, the rapid increase in the use of social media may allow for greater civil society mobilisation and organisation, thereby generating greater demand for social protection.

In terms of economic factors, issues regarding economic growth and economic volatility were discussed in the online discussion and key informant interviews. High levels of economic growth in many developing countries and the reclassification of low-income as middleincome countries, gave rise to the question as to whether the demand for social protection will expand among the growing middle classes. A strong focus on economic growth as a development objective is also increasing the pressure on social protection to demonstrate positive impacts on inequality, productivity and growth (World Bank 2012). This could increase political support for social protection, but could also divert attention from its main objective - to protect people against risks and reduce vulnerability (de Haan 2014). Several key informants emphasised the importance of reconciling the objectives of economic growth and reducing inequality and the role of social protection in such inclusive pro-poor growth.

Recent financial crises and economic volatility were referred to many times as suggesting a greater need for social protection. The financial crisis in 1997-8 in Southeast Asia acted as a wake-up call regarding the inadequacy of existing social safety nets and proved an important milestone in the region's development of social protection (Cook 2009). Nonetheless, it was pointed out that recent crises have not yet raised enough awareness about the need for social protection. Further economic factors identified in the workshops include the changing levels and characteristics of poverty, increasing flexibilisation of labour markets and shifts in private versus public service provision, including a potential for more public-private partnerships in the delivery of social protection.

Environmental drivers of change were identified in relation to climate change and revenue from natural resources. Poor people in rural areas whose livelihoods depend on natural resources are likely to be impacted negatively by changes in the natural environment. The consequences of climate change, including recurring disasters, as well as the unpredictability of the weather and consequently agricultural productivity, are increasing the need for social protection to mitigate livelihood risks (ESCAP 2011). Many online discussants and key informants pointed towards the role of social protection in making people more resilient to climate shocks by supporting them to adapt their livelihoods. Notwithstanding the importance that climate change 
will play in shaping the world in 10 to 15 years' time, this is an area where opinion is sharply divided, with one view being that climate change will continue to rise up the agenda and that social protection offers an appropriate response, and an opposing view being that social protection has only a marginal role in addressing the fundamental challenges to livelihoods that climate change poses.

Political drivers were considered crucial in shaping the future world that social protection will be part of and to which it will need to respond. These drivers were identified as operating at different levels and include global development paradigms, political realities in donor countries and political commitment at national level. Inequality is widely seen as a major force that could drive a rationale for social protection and create a political incentive within the global development paradigm. Reducing inequality - encompassing income inequality and inequalities along socio-demographic characteristics - is also a 'hot topic' in current development debates, and social protection is often mentioned as one of the main policy instruments to achieve this.

How this will happen is still unclear and it could go in different directions: will growing inequalities cause greater social schisms and the development of parallel systems (comfortable social security for the better off, and meagre poor relief for the poor), or will they fuel demands for more universal and redistributive social protection systems? At the regional level in Africa, for example, the African Progress Panel and the African Development Bank are emphasising the need for governments to step up their investments in health, education and social protection, with a view to moving towards universal access to these basic social services. Consolidating regional integration and harmonising social security will help to address challenges posed to social security systems, for example by migrant workers.

This leads into a second political driver, namely the political reality in donor countries, or influential countries that have a strong impact on policy in developing countries. 'Chindia' was coined as a term during the workshops to denote the expanding and increasingly important role of China and India in developing countries. Whether the political climate in countries that are driving social protection as a global development policy agenda is 'progressive' (rights-based) or 'regressive' (austerity-driven), has profound implications for levels of financing and the nature of technical support offered. While progressive agendas may be supportive of more universal and redistributive systems that are embedded in legal frameworks, regressive policies are more likely to focus on maintaining the status quo and providing only discretionary support to those in absolute need.

While international agreements, UN conventions and donor agendas can put social protection into the limelight and provide the tools for establishing social protection systems, whether this translates into action will ultimately depend on political commitment at the national level. 
Figure 2 Scenarios

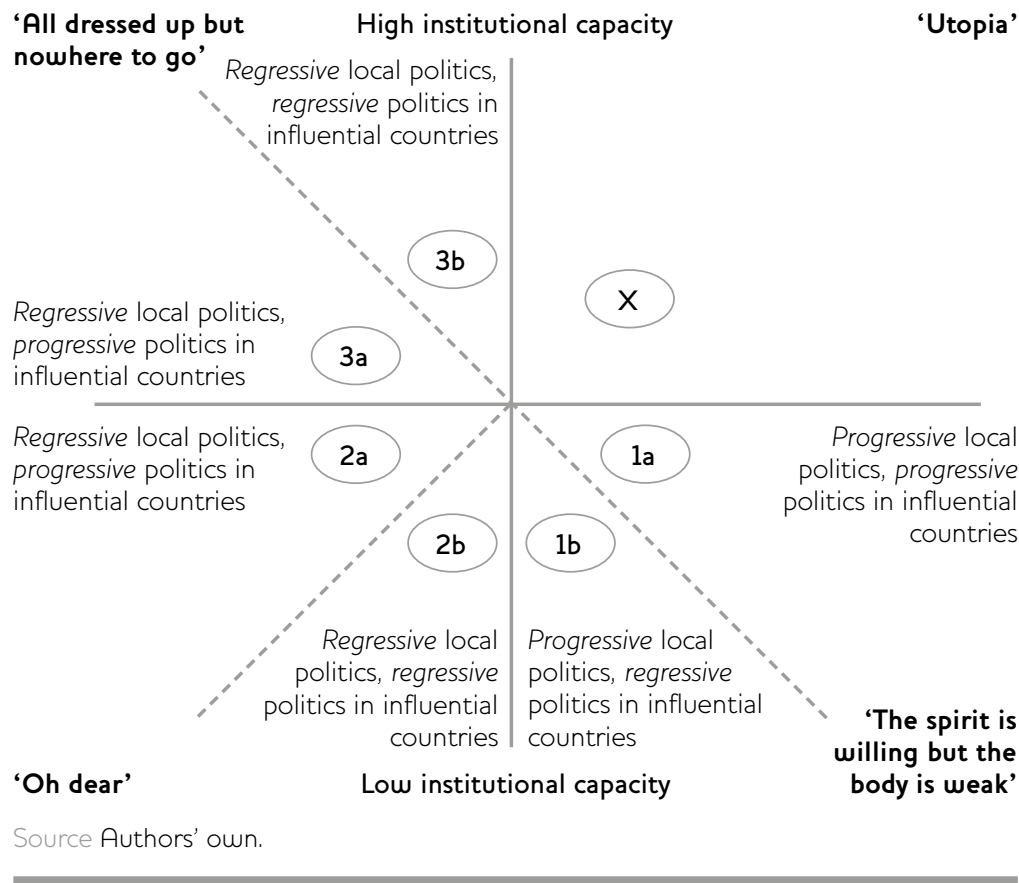

What determines such political commitment will be context-specific. Democratic processes and the ability of society to organise itself and influence welfare policies are thought to be essential. At the same time, countries such as Ethiopia, Rwanda, China and Vietnam may not fit such a characterisation of their political contexts but have seen strong commitment to and expansion of social protection. National ownership of social protection programmes is emerging unanimously as a necessary pre-condition for the sustainability of programmes, and forms a strong pillar of social protection strategies.

Yet, how and why governments decide on committing to social protection is highly context-specific. Frequently, the popularity of social protection is explained along social-democratic (or Polanyian) lines growing inequalities and vulnerabilities trigger expansions of public policies. There is, however, no direct causality between increasing needs (demand) and increasing delivery of social protection (supply), since it leaves the political drivers of social policies out of the equation (de Haan 2014). Public and political opinions on social provisioning and the role of the state are deeply ideologically motivated.

In some regions, political commitment will derive from a determination to uphold the rights of citizens. Nevertheless, it may also be strongly influenced by immediate political pressures, particularly in electoral democracies, or by longer-term considerations if social stability is seen as critical to political legitimacy (ESCAP 2011; Cecchini and Martínez 2012). In other contexts where social protection is externally financed, policy processes and sources of financing are still detached. Evidence is 
built around 'what works' rather than on what kind of evidence will be credible and useful to influence national policy processes (Devereux and White 2010; Gentilini and Omamo 2011).

This ties into a final driver that was discussed extensively during the workshops, namely that of institutional capacity. What levels of financial, human and technical resources do countries have (or are willing to dedicate) for social protection programmes, and do they have institutions strong enough to deliver them effectively?

\section{Future scenarios}

\subsection{Scenario building}

Following the identification of drivers of change likely to shape the world in which social protection operates, two drivers were selected to underpin the 'scenario-building' exercise: 'progressive/regressive politics' and 'high/low national institutional capacity'. These were subsequently placed on a continuum on an $\mathrm{x}$-axis and $\mathrm{y}$-axis respectively, such that four potential scenarios emerged (corresponding to the quadrants in Figure 2):

'Utopia' (top right): progressive politics, high capacity

'The spirit is willing but the body is weak' (bottom right): progressive politics, low capacity

'All dressed up but nowhere to go' (top left) regressive politics, high capacity

'Oh dear' (bottom left): regressive politics, low capacity.

It was decided that the 'ideal' scenario (top right - 'Utopia') would not be discussed as it was considered to be the least interesting scenario for further exploration, and least likely to occur in low-income countries where social protection is currently being introduced or expanded.

In the process of scenario building, however, it became evident that the driver on 'politics' was not specific enough and conflated political processes at two different levels: (1) national or local level and (2) global or 'influential countries' level, where influential countries are those dominating the design and financing of social protection programmes in low-income countries. Sub-dividing the politics driver to account for this bifurcation resulted in the emergence of six scenarios for further exploration.

To keep the analysis manageable, it was decided to choose one slice (a) or (b) - of each quadrant, and in order to maximise diversity, the following scenarios were chosen for further elaboration: Scenario la: 'The spirit is willing...'; Scenario 2a: 'Oh dear'; and Scenario 3b: 'All dressed up...'

Scenario 1a: 'The spirit is willing...' (progressive local politics, progressive international politics, low institutional capacity). In this scenario there exists goodwill and good intentions, both domestically 
and internationally, but limited capacity to deliver social protection and other services effectively. Factors that might hold back progress in this scenario include: high or rising civil insecurity, food price and climaterelated shocks, a youthful population with low skills, the dominance of the private sector over societal interests, and rising social frustrations about government failures leading to service delivery protests.

Positive features of this scenario include: an alignment of national governments and donors and development partners around what needs to be done, high aid flows with a particular emphasis on strengthening institutional capacity and technical expertise, an active civil society which could be strengthened and rights-based policies - at least on paper. There is potential for technology to help tackle or bypass delivery challenges. There is a risk of donor dependence or that social experiments will be trialled as pilot projects. Social protection initiatives that are launched in this context might be unsustainable because they rely heavily on expatriate financial and technical inputs, and government lacks the capacity to take over their management and scale them up.

Scenario 2a: 'Oh dear' (regressive local politics, progressive international politics, low institutional capacity). This scenario is characterised by high levels of poverty and inequality. Citizens have no voice and civil society is weak or repressed, so government is effectively unaccountable. Civil society exists mainly as implementing partners for development projects of international donors, rather than as activists campaigning for change. Government has no interest in rights-based approaches, clientelism is rife, public provision of services is weak, the middle classes depend on private social services, and there is low commitment by public officials to help the poor.

Apart from the dire political situation, the economic situation is equally challenging. Labour markets are insecure with a large informal sector and unregulated markets; there is little social protection against livelihood shocks such as extreme weather events, price shocks and financial crises; people face multiple vulnerabilities, such as high health risks and low health outcomes. Because of these political and economic challenges, there is extensive 'economic' migration within and between countries, including unplanned and poorly serviced urban informal settlement, as well as 'political' migration inside and beyond national boundaries (population displacement, refugees). International actors have a limited role, which is often restricted to humanitarian relief.

Scenario 3b: 'All dressed up...' (regressive local politics, regressive international politics, high institutional capacity). Because politics in this scenario are regressive both locally and internationally, external relations are dominated by 'trade, not aid' - international trade agreements rather than aid flows. The labour market is stagnant and unemployment is high. There is inadequate state regulation of private sector employers. This is a low-wage economy dominated by informalisation. Societal 
expectations and ambitions are low. Those who can, migrate to more vibrant economies in more progressive countries elsewhere.

Because local capacity is relatively high, financing for social protection is generated by economic growth and a mix of public and private provision. However, only a minimal safety net is installed, to quell social unrest. Public expenditure is rolled back and public sector budgets are cut for ideological reasons. Social insurance is based on private contributions while social assistance comes with conditionalities attached. This leads to rising inequality and polarisation, with limited redistribution of public resources and few groups being adequately covered by government-run social protection programmes.

\section{Wind-tunnelling}

The wind-tunnelling exercise aimed to formulate policy options for social protection within these three scenarios. The focus was on identifying viable and feasible options in the three different 'future worlds'. Policy options formulated for one scenario were subsequently 'tested' against the other scenarios to assess their feasibility and opportunities for application in radically different contexts. Discussions on the basis of this exercise are summarised here.

Scenario 1a: 'The spirit is willing...' Proposed policy options included: building consensus on a single national vision and platform for social protection; using technical assistance in innovative ways to strengthen local capacity; signing up to the Social Protection Floor and adopting a 'progressive realisation' approach to achieving it, increasing public demand for social services, including accountability mechanisms such as grievance procedures, and introducing right-to-work schemes (employment guarantees rather than public works projects). All of these proposals were agreed to be appropriate in a context of progressive local and international political regimes but low institutional capacity.

These proposals received mixed reactions from Scenarios 2a and $3 \mathrm{~b}$. There was little enthusiasm for a national vision and no interest at all in signing up to the Social Protection Floor, which was dismissed as 'too progressive'. Public services would be delivered alongside private providers and there would definitely be no accountability mechanisms. The 'right-to-work' proposal was rejected in favour of old-style public works: 'No right to work, but a duty to work'.

Scenario 2a: 'Oh dear' Proposed policy options were very limited and unambitious, reflecting the limited commitment and accountability of this regressive regime and its low capacity to deliver public services. Social protection would effectively take its most basic 'safety net' forms: humanitarian response during crises (probably delivered by international agencies rather than the government), public works projects (also externally funded and run by donors or NGOs), mother and child feeding schemes, and contributory pensions for civil servants as part of the government's clientelist orientation. 
The regressive government of Scenario $3 \mathrm{~b}$ endorsed these suggestions, as both regimes share a common ideology. But since Scenario 3b has higher capacity to deliver services, the government would be the main implementing agency for all interventions. The progressive government of Scenario la did not oppose these ideas in principle, but would implement them as part of a coordinated national vision for social protection rather than as isolated projects. Contributory pensions for civil servants would only be acceptable as one component of a universal pension scheme.

Scenario 3b: 'All dressed up...' Policy options in this scenario were highly regressive. The regime is assumed to be pro-business so deregulation of business is favoured, implying low social security coverage and contributions, and no minimum wage to protect low-paid workers against exploitation. Social protection will be dominated by conditionalities and a focus on graduating people off programmes and into the labour market as quickly as possible. Minimal social assistance will take the form of food banks that will be run by the non-profit third sector plus private partnerships.

The equally regressive government of Scenario 2a supported these proposals in principle, but noted that international donor partners might not endorse excessive deregulation of the private sector and restricted social security protections for workers. They might also lack the capacity to implement graduation programmes, even while agreeing with the intention behind them. The government of Scenario la disapproved of this entire set of proposals on ideological grounds. Favouring business, conditionalities, graduation and soup kitchens are all antithetical to the more pro-poor and rights-based orientation of this progressive regime and its progressive international partners.

This exercise revealed that the fundamental determinant of a country's social protection trajectory is likely to be the nature of that country's political regime. A progressive government will be open to rightsbased approaches such as the Social Protection Floor and employment guarantee schemes, civil society mobilisation and accountability mechanisms. Low institutional capacity can be partly rectified with the support of development partners, especially if the international political climate is also progressive. Conversely, regressive governments will reject rights-based approaches in favour of minimalist safety net approaches such as food banks, public works projects and limited conditional cash transfers. The economic and political contexts will be conducive to business and the private sector, and contributory social security for formal employees is preferred to large-scale social assistance programmes such as social grants.

The exercise further revealed that the role of the international political regime is likely to be limited. While it may be important in creating an enabling environment for progressive and innovative policy design (through the launch of global initiatives such as the Social Protection 
Floor and provision of technical assistance, for example) or acting as a brake on regressive interventions, it is unlikely to form a decisive factor in shaping national social protection landscapes.

\section{Conclusion}

As noted earlier, this is not a conventional study that investigated a research question or hypothesis in order to draw out recommendations for improved practice from the empirical findings. Instead we used a variety of methods and tools to draw out a range of views on possible future trajectories for social protection as a policy domain in low- and middle-income countries, and we have presented these views without imposing our own prejudices or a false consensus where none exists.

At the start of the online discussion event for this project, registered participants were asked to vote on whether they believe that social protection will grow, stabilise or decline in the next five to ten years. Responses were overwhelmingly optimistic. No less than 87 per cent (63 of 72 who answered) predicted that social protection will continue to grow, 10 per cent thought it will stabilise at its current level, and only 3 per cent believed that it will start to decline from its present position on the development policy agenda.

Key informants interviewed for this project expressed a diversity of views on this question. Many shared the dominant view that social protection will continue to rise on national policy agendas, while others predicted that social protection will reach a natural plateau fairly soon. A few key informants reflected the minority view that social protection will decline, especially at the level of the global development policy discourse.

Reinforcing the pre-discussion vote, the dominant view among the online participants, as well as key informants, was that social protection will continue to become more prominent on the development agenda in the next five to ten years, for both 'demand-side' and 'supply-side' reasons.

On the demand side, social protection will grow because there will be a continual increasing need for it. Social protection can help in bridging inequality and reducing vulnerability. It can function as a stabilising force post-crisis (economic and political) and address social exclusion of the poorest. However, the increasing need for social protection should not be taken as a sign of its success, if it is used instrumentally as a 'band-aid' for failed economic strategies and systemic failure.

On the supply side, social protection is increasingly gaining political support. The demand will be met because there is increasing political interest in supplying social protection. The last decade has seen an exponential growth in the number of developing countries that are introducing social protection programmes. Countries like Brazil and Mexico in Latin America, or Rwanda and Ethiopia in Africa, have pioneered national social protection programmes that have served as models for their regions. Some countries, such as South Africa and India, have even integrated legal provisions for social protection into their 
constitutions. This trend will not only continue, but it will likely move towards a more holistic agenda linked to the provision of basic services, such as health and education, as well as to economic sectors such as agriculture and job creation. Political will and national ownership remain decisive in the evolution of national social protection systems.

It is never easy to predict the future, but a few projections can be made with some degree of confidence. Social protection will continue to consolidate, especially in middle-income countries, where projects and programmes will increasingly become components of integrated systems with linkages to other social and economic sectors and (where appropriate) harmonised financial and technical support from development partners. Challenges of affordability and extending coverage will persist in low-income countries - there might even be reversals in unfavourable economic and political contexts.

Economic shocks and political crises, whether at national, regional or global level, will continue to either undermine the deepening of social protection systems or will motivate increasing investments in building systems to protect people against the consequences of these shocks this could go either way. Social protection will increasingly become a response to income inequality and social inequities rather than being driven only by poverty and demographic vulnerabilities. It is not yet clear whether rights-based approaches towards universal provision underpinned by justiciable legislation, such as the Social Protection Floor, will gain traction globally or only in certain countries.

The governance of social protection will gain increasing attention, particularly with respect to such issues as decentralised programming, the role of civil society, and bottom-up social accountability mechanisms. Development partners will need to redefine their role, probably moving away from financing social protection projects directly and building the evidence base on impacts, towards innovative approaches to technical support and building national capacities.

Ultimately, the direction that social protection takes will vary from country to country and will shift over time, as capacities to deliver fluctuate and as governments and political ideologies change. Better understanding of political processes around social protection, and innovative approaches to building institutional capacity, are essential to consolidate progress and to exploit both 'progressive' periods and times of austerity as windows of opportunity for reshaping social protection, as it moves forward into its next phase.

\section{Notes}

* This article draws on Devereux, S.; Roelen, K. and Ulrichs, M. (2015) Where Next for Social Protection?, IDS Evidence Report 124, Brighton: IDS. 


\section{References}

ADB (2013) The Social Protection Index - Assessing Results for Asia and the Pacific, Mandaluyong City: Asian Development Bank

Cecchini, S. and Martínez, R. (2012) Inclusive Social Protection in Latin America: A Comprehensive, Rights-based Approach, Santiago: United Nations

Cook, S. (2009) 'Social Protection in East and Southeast Asia: A Regional Review', paper prepared as part of a Social Protection Scoping Study funded by the Ford Foundation, Brighton: IDS

de Haan, A. (2014) 'The Rise of Social Protection in Development: Progress, Pitfalls and Politics', European Fournal of Development Research 26: $311-21$

Devereux, S. and Sabates-Wheeler, R. (2004) Transformative Social Protection, IDS Working Paper 232, Brighton: IDS

Devereux, S. and White, P. (2010) 'Social Protection in Africa: Evidence, Politics and Rights', Poverty and Public Policy 2.3: 53-77

ESCAP (2011) The Promise of Protection: Social Protection and Development in Asia and the Pacific, Bangkok: United Nations Economic and Social Commission for Asia and the Pacific

Gentilini, U. and Omamo, S.W. (2011) 'Social Protection 2.0: Exploring Issues, Evidence and Debates in a Globalizing World', Food Policy 36: 329-40

Hickey, S. (2008) 'Conceptualising the Politics of Social Protection in Africa', in A. Barrientos and D. Hulme (eds), Social Protection for the Poor and Poorest: Concepts, Policies and Politics, London: Palgrave

ILO (2014) World Social Protection Report 2014/15 - Building Economic Recovery, Inclusive Development and Social Justice, Geneva: International Labour Organization

ILO (2011) Social Protection Floor for a Fair and Inclusive Globalization, Report of the Advisory Group Chaired by Michelle Bachelet, Geneva: International Labour Organization

Niño-Zarazúa, M.; Barrientos, A.; Hulme, D. and Hickey, S. (2012) 'Social Protection in Sub-Saharan Africa: Getting the Politics Right', World Development 40.1: 163-76

World Bank (2012) The World Bank 2012-2022 Social Protection and Labor Strategy: Resilience, Equity and Opportunity, Washington DC: World Bank

World Bank (2001) Social Protection Sector Strategy: From Safety Net to Springboard, Washington DC: World Bank 
This page is intentionally left blank 